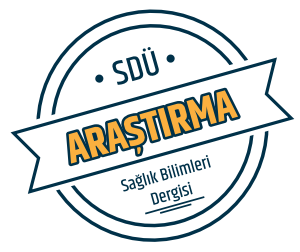

Sdü Sağlık Bilimleri Dergisi / Cilt 10 Sayı 3 / 2019

\title{
Akne Vulgaris Hastalarında Mizaç ve Dürtüsellik
}

\section{Temperament and Impulsivity in Acne Vulgaris Patients}

\author{
Faruk Kılıç¹, Selma Korkmaz², İjlal Erturan², Ümit Işık, \\ Arif Demirdaş ${ }^{1}$, İnci Meltem Atay ${ }^{1}$, Duru Kuzugüdenlioğlu Ulusoy ${ }^{1}$ \\ ${ }^{1}$ Süleyman Demirel Üniversitesi Tıp Fakültesi, Psikiyatri Anabilim Dalı, Isparta, Türkiye. \\ ${ }^{2}$ Süleyman Demirel Üniversitesi Tıp Fakültesi, Dermatoloji Anabilim Dalı, Isparta, Türkiye.
} ${ }^{3}$ Süleyman Demirel Üniversitesi Tıp Fakültesi, Çocuk ve Ergen Ruh Sağlığı ve Hastalıkları Anabilim Dalı, Isparta, Türkiye.

\section{Özet}

Amaç: Akne Vulgaris (AV) pilosebase üniteyi etkileyen bir hastalıktır. Mizaç, stres ve psikososyal faktörler AV'in başlangıcında ve alevlenmesinde önemli bir rol oynar. Bu nedenle AV hastalarında eşlik eden ruhsal sorunlar, dürtüsellik ve mizaç özelliklerinin belirlenmesi hastalık ile mücadelede klinisyenlere yararlı bilgiler sağlayacaktır. $\mathrm{Bu}$ çalışmanın amacı AV'li hastaların mizaç, dürtüsellik, depresyon ve anksiyete düzeylerinin değerlendirilmesidir.

Materyal-Metot: Çalışmaya AV tanılı 59 hasta ile 40 sağlıklı kontrol dahil edildi. Grupların sosyodemografik özellikleri kaydedildikten sonra Beck Depresyon Ölçeği (BDÖ), Beck Anksiyete Ölçeği (BAÖ), Barratt Dürtüsellik Ölçeği 11. versiyon (BDÖ-11), Temperament Evaluation of Memphis, Pisa, Paris, San Diego Autoquestionaire (TEMPS-A) ölçekleri uygulandi. Ayrica hasta grubuna klinik şiddeti belirlemek için GADS (Global Akne Derecelendirme Sistemi) ve VAS (Vizüel Aktivite Skoru) ile Dermatoloji Yaşam Kalitesi Endeksi (DYKE) uyguland1.

Bulgular: AV'li hastaların siklotimik mizaç ve irritabl mizaç puanları anlamlı olarak daha yüksekti. Hasta grubunda dürtüsellik puanları anlamlı olarak daha yüksek idi. Hastaların yaşam kalitesi 38 hastada $(\% 64,4)$ az etkilenmiş veya etkilenmemiş, 21 hastada $(\% 35,6)$ orta düzeyde veya çok etkilenmiş olarak saptandı. Orta-çok etkilenen grupta az etkilenen gruba göre anksiyete ve depresyon puanları anlamlı olarak daha yüksekti.

Sonuç: Çalışmamızda AV'li hastalarda siklotimik ve irritabl mizaç puanlarını anlamlı ölçüde yüksek bulduk. Ayrıca AV'li hastaların dürtüsellik düzeylerinin daha fazla olduğunu saptadık. Sonuç olarak, mizaç ve kişilik özelliklerini anlamak, AV'in tedavisi sirasında hastalar ve doktorlar arasında işbirliğine dayalı bir iletişimin kurulmasında temel oluşturacaktır.

Anahtar kelimeler: Akne Vulgaris, Mizaç, Dürtüsellik, Yaşam Kalitesi.

\begin{abstract}
Objective: Acne Vulgaris (AV) is a disease affecting the pilosebaceous unit. Temperament, stress and psychosocial factors play a significant role in the initiation and exacerbation of the disorder. Therefore, accompanying mental problems, impulsivity and temperament characteristics in AV patients will provide useful information to clinicians in struggling disease. The aim of this study was to evaluate temperament, impulsivity, anxiety and depression in patients with AV.
\end{abstract}

Material-Method: A total of 59 patient with acne vulgaris and 40 healthy controls were included in the study. Beck Depression Inventory (BDI), Beck Anxiety Inventory (BAI), Barratt Impulsivity Scale 11 th version (BIS-11), Temperament Scale of Memphis, Pisa, Paris and San Diego Autoquestiona Scales (TEMPS-A) were applied. In addition, GADS (Global Acne Rating System) and VAS (Visual Activity Score) and Dermatology Quality of Life Index (DLQI) were applied to the patient group.

Results: Cyclothymic temperament and irritable temperament scores were significantly higher in the patient group. Impulsivity scores were significantly higher in the patient group. The patients' quality of life was found to be less affected or unaffected in 38 patients $(64.4 \%)$ and was moderate or highly affected in 21 patients $(35.6 \%)$. Anxiety and depression scores were significantly higher in the moderate-affected group compared to the less affected group.

Conclusions: In our study, we found significantly higher cyclothymic and irritable temperament scores in AV patients. We also found that impulsivity levels of AV patients were higher. As a result, understanding the temperament and personality traits will provide the basis for establishing a cooperative communication between patients and doctors during the treatment of these chronic skin diseases.

Keywords: Acne Vulgaris, Temperament, Impulsivity, Quality of Life.
DOI: $10.22312 /$ sdusbed. 568555

Müracaat tarihi / Received date: 10.04 .2019

Kabul tarihi / Accepted date: 02.08.2019

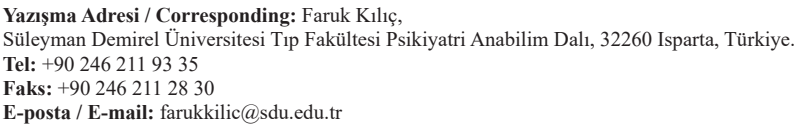




\section{Giriş}

Deri ruhsal hastalıklarla yakın bir ilişki içinde olup, bireyin psikolojik durumunu ve mizacını yansıtan, vücudun en önemli organlarından biri olarak kabul edilmektedir (1). Deri ve santral sinir sistemi aynı ektodermal kökene sahip olup öfke, utanç, heyecan ve korku gibi duyguları ifade etme aracı olarak, beden algısı ve benlik saygısının gelişmesinde önemli rol oynar $(1,2)$. Akne Vulgaris (AV) pilosebase bezlerin kronik inflamatuar bir hastalığı olup gençlerde ve yetişkinlerde oldukça sık görülen bir bozukluktur (3-5). AV sıklığının ergenlerde ve genç erişkinlerde \%30-\%85 arasında olduğu bildirilmiş olup nadiren ileri yaşlarda da görülebilmektedir (6). AV prevalansı erkeklerde $\% 3$, kadınlarda \%11-12'dir (7, 8).

Mizaç, karakter ve kişilik kavramları bireyin temel doğasına atıf yapan yapılardır. Mizaç kişiliğin istikrarlı temel yapısıdır, kişinin sürekli kalıcı özellikleri ile geçici durumsal özellikleri arasındaki temel sürekliliği temsil eder (2). Akiskal modern afektif mizaç kavramını formüle edip beş afektif mizaç tanımlamıştır. Depresif mizaç içe kapanma, karamsarlık, düşük benlik saygısı, kötümserlik, alınganlık ve utangaçlık gösterir. Siklotimik mizaç duygudurum, benlik saygısı, enerji ve uykuda hızlı değişimlerle karakterizedir. Hipertimik mizaç özellikleri canlı, aşırı enerji ve özgüvenin arttığı, yüksek benlik saygısı, risk alma ve sosyallik ile karakterizedir. İritabl mizaç disforik duygudurum, huzursuzluk, saldırganlık ve eleştirici özellikler gösterir. Anksiyöz mizaç özellikleri ise üzücü, kaygıya karşı abartılı bir eğilim gösterme, günlük değişimlere adaptasyonda zorluk, psikosomatik rahatsızlıklara yatkınlık ile karakterizedir $(2,9)$.

AV'li hastaların diğer dermatoloji hastalarında olduğu gibi değişken bir duygulanıma sahip, nörotik kişilik özellikleri olduğu ve ruhsal bozukluklara yatkın oldukları belirtilmektedir $(10,11)$. AV'den muzdarip hastaların yaşadığı anksiyete, depresyon, ve azalmış benlik saygısı gibi duygular kişilerarası ilişkiyi olumsuz yönde etkileyebilir (12). Bu tür olumsuzluklar bireyin günlük yaşamında uygunsuz kaçınma davranışlarına yol açabilir. Kişiliğin baskın olarak erken yaşlarda geliştiği göz önüne alındığında bu durumun bireyin mizaç yapısında sürekli sorunlar yaşayabileceğini düşündürebilir (13). AV fiziksel görünüm, benlik imajı ve benlik saygısı üzerine olan etkisiyle, kişiliğin büyük oranda geliştiği ergenlik döneminde önemli bir sorun oluşturacağı için bireyin kişilik gelişiminde olumsuz bir etkiye yol açabilir. Ayrıca, AV ergenlikte yaratabileceği anksiyete, depresyon ve benlik saygisında azalma ile birlikte bireyin kişilerarası ilișkilerinde de güçlüklere yol açabilir. Bu olumsuzluklar sonucunda bireyin yaşamındaki zorluklar ile başa çıkmasında uyumsuzluk gelişebilmekte ve bu durum benlik algısındaki olumsuzlukları güçlendirip mizaç özelliklerinde kalıcı izler birakabilmektedir (14).

Mizaç, stres ve psikososyal faktörler AV'in başlangıcında ve alevlenmesinde önemli bir rol oynar. Bu nedenle AV hastalarında eşlik eden ruhsal sorunlar, dürtüsellik ve mizaç özelliklerinin belirlenmesi hastalık ile mücadelede klinisyenlere yararlı bilgiler sağlayacaktır. Bu özellikleri göz önüne alarak tedaviye eklenecek psikofarmakolojik ve/veya psikoterapinin tedavi sürecine olumlu katkıları olacağını düşünmekteyiz. Bu nedenle çalışmamızda AV hastalarının TEMPS-A ölçeği ile mizaç özelliklerini belirleyip klinik değişkenlerle ilişkisi değerlendirilmiştir.

\section{Materyal-Metot}

Bu araştırma Süleyman Demirel Üniversitesi Tıp Fakültesi Araştırma ve Uygulama Hastanesi Dermatoloji polikliniğine başvuran hastalar arasında yapıldı. Çalışmaya deneyimli dermatoloji uzmanı tarafindan klinik olarak AV tanısı konulan olgular arasından çalışma kriterlerini karşılayan 59 hasta alınmıştır. Hasta grubuna benzer özellikler taşıyan 40 sağlıklı gönüllü çalışmaya alındı. Her iki grupta psikiyatrik tedavi gören veya psikotrop ilaç kullanımı olan, alkol veya başka bir madde zararlı kullanımı olanlar, sistemik veya metabolik hastalığı olanlar, nörolojik bozukluğu olanlar çalışmaya alınmadı. Katılımcılardan bilgilendirilmiş olur alındı. Katılımcıların sosyodemografik özellikleri kaydedildikten sonra Beck Depresyon Ölçeği (BDÖ), Beck Anksiyete Ölçeği (BAÖ), Barratt Dürtüsellik Ölçeği 11. versiyon (BDÖ-11), Temperament Evaluation of Memphis, Pisa, Paris, San Diego Autoquestionaire (TEMPS-A) ölçekleri uygulandi. Ayrıca hasta grubuna klinik şiddeti belirlemek için GADS (Global Akne Derecelendirme Sistemi) ve VAS (Vizüel Aktivite Skoru) ile Dermatoloji Yaşam Kalitesi Endeksi (DYKE) uygulandı. Çalışma için Süleyman Demirel Üniversitesi Tıp Fakültesi Klinik Araştırmalar Etik Kurulundan onay alındı.

\section{Araçlar}

TEMPS-A (Temperament Evaluation of Memphis, Pisa, Paris, San Diego Autoquestionaire) Mizaç Ölçeği: Afektif mizacı değerlendirmek üzere, Akiskal ve ark. tarafindan düzenlenmiştir (15). Ölçeğin Türkçe uyarlanmış hali 99 maddeden oluşmaktadır (16). Kişi tüm yaşamını göz önüne alarak maddeleri evet veya hayır şeklinde yanıtlar. Evet için 1, hayır için 0 puan verilir. Ölçekte depresif, siklotimik, hipertimik, irritabl ve anksiyöz mizaç değerlendirilmektedir. Baskın mizaç için kesme puanları sirasiyla 13, 18, 20, 13 ve 18 puandır.

Beck Anksiyete Ölçeği (BAÖ): 21 maddeden oluşan likert tipte değerlendirme ölçeğidir. Beck ve ark. tarafından geliştirilen ölçek, anksiyete belirtilerinin yaygınlığının belirlenmesi için kullanılmaktadır (17). Ülkemizde güvenilirlik ve geçerliliği Ulusoy ve ark. tarafından yapılmıştır (18). Alınabilecek en düşük ve en yüksek puan 0-63' tür. Ölçekten alınan puanlara göre bireylerin anksiyete düzeyleri; 0-17 puan düşük, 18- 24 puan orta, 25 ve üzeri puan yüksek düzeyde anksiyete şeklinde gruplandırılmıştır.

Beck Depresyon Ölçeği (BDÖ): Aeron Beck ve ark. (19) tarafından geliştirilmiştir. Ölçek puanlaması şu şekilde değerlendirilmektedir; 0-13 arası depresyon olmadığını, 14-19 arası düşük, 20-28 arası orta, 29-63 arası puan yüksek düzeyde depresyon olarak sınıflandırılmıştır. En düşük ve en yüksek puan 0-63' tür. Ülkemizde güvenilirlik ve geçerlilik çalışması Hisli tarafindan geliştirilmiştir (20).

Global Akne Derecelendirme Sistemi (Global Acne Grading System, GADS): Doshi ve ark. tarafından geliştirilmiştir (21). Akne şiddetini, aknenin vücuttaki dağılımı ve lezyon tipine göre puanlayan bir ölçme sistemidir. Puanlamada papül, püstül, komedon ve nodül değerlendirilir. Derece hesaplanırken 0-4 puanları kullanılır. Her bir vücut bölgesi için puanlar verilir. Bunların toplanması ile toplam puan elde edilir.

Dermatolojide Yaşam Kalite Índeksi (DYKİ): 1997'de Finlay tarafindan geliştirilmiştir (22). Bütün dermatolojik hastalıklara uygulanabilen bir ölçektir. Bireyin hastalığını değerlendirmesi 
ve yarattığı anksiyeteyi belirlemede oldukça faydalıdır. Toplam 4 muhtemel yanıtın olduğu 10 sorudan oluşmaktadır. Alınan yüksek puan düşük yaşam kalitesini gösterir. 0-5 puan aralığı hastalıktan etkilenmeme veya az etkilenme, 5-11 puan arası orta düzeyde, 11 puan üzeri ise çok etkilenme olarak değerlendirilmektedir. Türkçe geçerlilik ve güvenirliği Öztürkcan ve ark. tarafindan yapılmıştır (23).

Barratt Dürtüsellik Ölçeği 11. versiyon (BDÖ-11): Dürtüselliği ölçen, 30 maddeden oluşan kendini değerlendirme ölçeğidir. Dikkat, motor ve tasarlanmamış dürtüsellik şeklinde 3 alt ölçeği vardır. Yüksek puanlar dürtüsellik düzeyinin yüksekliğini gösterir. Türkçe geçerlilik ve güvenilirlik çalışması Güleç ve ark. (24) tarafindan yapılmıştır.

\section{İstatistiksel Değerlendirme}

Verilerin analizinde "SPSS for Windows 18.0" paket programı kullanıldı. Verilerin dağılımı Kolmogorov-Smirnov testi ile değerlendirildi. Dağılımı normal olan veriler Student t testiyle, normal dağılımı olmayanlar ise Mann Whitney $U$ testi ile değerlendirildi. Kategorik veriler için ki-kare testi uygulandi. Elde edilen veriler ortalama ve standart sapma ile gösterildi. Veriler arasındaki ilişki Pearson ve Spearman korelasyonuyla incelendi. Sonuçlar \%95'lik güven aralığı ve anlamlılık p $<0,05$ olacak şekilde değerlendirildi.

\section{Bulgular}

Çalışma 59 AV'li hasta ve 40 sağlıklı kontrol ile yapılmıştır. Hasta ve kontrol grupları sosyodemografik veriler açısından

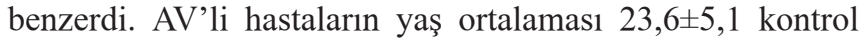
grubunda ise 24,7 $\pm 5,7$ idi. Hasta grubunda 32 kadın 27 erkek, kontrol grubunda ise 24 kadın ve 16 erkek vardı. Hastaların 9'u evli, 50'si bekar, kontrol grubunun 12'si evli, 28'i bekar idi. Hastaların 1'i ilköğretim, 9'u lise, 49'u üniversite, kontrol grubunda 3'ü ilköğretim, 7'si lise, 30'u üniversite mezunu idi (Tablo 1).

Anksiyete ve depresyon puanları kıyaslandığında gruplar arasında anlamlı bir farklılık saptanmamıştır (Tablo 1). Hasta grubunda baskın mizaç olarak iki kişide irritabl mizaç, bir kişide anksiyöz mizaç saptandı. Kontrol grubunda baskın mizaç saptanmadı. Grupların mizaç puanları değerlendirildiğinde hasta grubunda siklotimik mizaç $(\mathrm{p}=0,015)$ ve irritabl mizaç $(\mathrm{p}=0,010)$ puanları anlamlı olarak daha yüksekti (Tablo 2$)$. Depresif, hipertimik ve anksiyöz mizaç puanları gruplar arasında farklılık göstermedi (Tablo 2).

Hasta ve kontrol gruplarında dürtüsellik puanları kıyaslandığında, hasta grubunda tasarlanmamış dürtüsellik $(\mathrm{p}=0,001)$, motor dürtüsellik $(\mathrm{p}<0,001)$, dikkat ile ilgili dürtüsellik $(p<0,001)$ ve toplam dürtüsellik $(p<0,001)$ puanları anlamlı olarak daha yüksek idi (Tablo 2).

Hasta grubunda, DYKI toplam puanları minimum 0 ve maksimum 22 olup, ortalama 3,83 $\pm 4,90$ idi. Hastaların yaşam kaliteleri 38 hastada $(\% 64,4)$ az etkilenmiş veya etkilenmemiş olarak saptanırken, 21 hastada $(\% 35,6)$ orta düzeyde veya çok etkilenmiş saptandi. Orta-çok etkilenen grupta az etkilenen gruba göre anksiyete $(p=0,001)$ ve depresyon $(p<0,001)$ puanları anlamlı olarak daha yüksekti. Ayrıca orta-çok etkilenen grupta siklotimik mizaç $(\mathrm{p}=0,010)$ ve dikkatle ilgili dürtüsellik puanları $(\mathrm{p}=0,033)$ anlamlı olarak daha yüksekti (Tablo 3).

Tablo 1. Grupların sosyodemografik, klinik, anksiyete, depresyon ve yaşam kalitesi skorları

\begin{tabular}{|c|c|c|c|}
\hline & $\begin{array}{c}\text { Akne } \\
\text { n:59 }\end{array}$ & $\begin{array}{c}\text { Kontrol } \\
\mathrm{n}: 40\end{array}$ & $\mathbf{p}$ \\
\hline Yaş & $23,66 \pm 5,10$ & $24,78 \pm 5,78$ & $0,477^{\mathrm{a}}$ \\
\hline \multicolumn{4}{|l|}{ Cinsiyet } \\
\hline Erkek & $27(\% 45,8)$ & $16(\% 40)$ & \multirow{2}{*}{$0,570^{\mathrm{t}}$} \\
\hline Kadın & $32(\% 54,2)$ & $24(\% 60)$ & \\
\hline \multicolumn{4}{|l|}{ Medeni durum } \\
\hline Evli & $9(\% 15,3)$ & $12(\% 30)$ & $0,078^{b}$ \\
\hline Bekar & $50(\% 84,7)$ & $28(\% 70)$ & \\
\hline \multicolumn{4}{|l|}{ Eğitim } \\
\hline İlköğretim & $1(\% 1,7)$ & $3(\% 7,5)$ & \\
\hline Lise & $9(\% 15,3)$ & $7(\% 17,5)$ & \\
\hline Üniversite & $49(\% 83,1)$ & $30(\% 75)$ & \\
\hline \multirow{2}{*}{ VAS } & $4,93 \pm 1,99$ & & \\
\hline & Min $0 \max 10$ & & \\
\hline \multirow{2}{*}{ GADS } & $14,78 \pm 8,18$ & & \\
\hline & Min2 $\max 33$ & & \\
\hline BAÖ & $7,92 \pm 8,39$ & $6,10 \pm 4,39$ & $0,816^{\mathrm{a}}$ \\
\hline BDÖ & $6,17 \pm 6,32$ & $6,03 \pm 4,81$ & $0,696^{\mathrm{a}}$ \\
\hline DYKI toplam & $3,83 \pm 4,90$ & & \\
\hline $\begin{array}{l}\text { Belirti ve } \\
\text { hasta hissi }\end{array}$ & $1,37 \pm 1,60$ & & \\
\hline Günlük aktivite & $0,69 \pm 1,16$ & & \\
\hline $\begin{array}{l}\text { Boş zaman } \\
\text { değerlendirme }\end{array}$ & $0,76 \pm 1,22$ & & \\
\hline Okul-iş hayatı & $0,36 \pm 0,86$ & & \\
\hline Kişisel ilişkiler & $0,36 \pm 0,73$ & & \\
\hline Tedavi & $0,29 \pm 0,55$ & & \\
\hline
\end{tabular}

VAS: Vizüel aktivite skoru, GADS: Global akne derecelendirme sistemi, DYKI: Dermatolojide yaşam kalite indeksi, BAÖ: Beck anksiyete ölçeği, BDÖ: Beck depresyon ölçeği, , ${ }^{\text {a }}$ mann whitney u test, : ki kare test

Tablo 2. Grupların mizaç ve dürtüsellik skorları yönünden karşılaştırılması

\begin{tabular}{lccc}
\hline & $\begin{array}{c}\text { Akne } \\
\mathbf{n}: 59\end{array}$ & $\begin{array}{c}\text { Kontrol } \\
\mathbf{n : 4 0}\end{array}$ & $\mathbf{p}$ \\
\hline Depresif mizaç & $5,29 \pm 2,78$ & $5,75 \pm 2,55$ & $0,436^{\mathrm{b}}$ \\
Siklotimik mizaç & $7,76 \pm 4,62$ & $5,65 \pm 4,38$ & $0,015^{\mathrm{a}^{*}}$ \\
Hipertimik mizaç & $9,27 \pm 4,34$ & $10,13 \pm 3,83$ & $0,317^{\mathrm{b}}$ \\
İrritabl mizaç & $4,05 \pm 3,48$ & $2,55 \pm 2,16$ & $0,010^{\mathrm{b}^{*}}$ \\
Anksiyöz mizaç & $6,14 \pm 4,76$ & $4,58 \pm 3,71$ & $0,164^{\mathrm{a}}$ \\
Toplam dürtüsellik & $64,10 \pm 8,88$ & $54,05 \pm 7,87$ & $<0,001^{\mathrm{b}^{* *}}$ \\
$\begin{array}{l}\text { Dikkat ile ilgili } \\
\text { dürtüsellik }\end{array}$ & $16,83 \pm 3,05$ & $12,88 \pm 2,71$ & $<0,001^{\mathrm{a}^{* *}}$ \\
$\begin{array}{l}\text { Motor dürtüsellik } \\
\text { Tasarlanmamiş }\end{array}$ & $21,08 \pm 4,17$ & $17,90 \pm 3,15$ & $<0,001^{\mathrm{a}^{* *}}$ \\
dürtüsellik & $26,19 \pm 4,15$ & $23,28 \pm 4,36$ & $0,001^{\mathrm{b}^{*}}$ \\
\hline${ }^{{ }^{a} \text { mann whitney u test, }{ }^{\mathrm{b}} \text { student t test, }{ }^{*} \mathrm{p}<0,05, * * \mathrm{p}<0,001}$ & &
\end{tabular}


Tablo 3. Hastalıktan etkilenme düzeyine göre mizaç ve dürtüsellik skorlar1

\begin{tabular}{lccc}
\hline & $\begin{array}{c}\text { Az / Etkilenmemiş } \\
\mathbf{( 3 8 )}\end{array}$ & $\begin{array}{c}\text { Orta / çok } \\
\text { etkilenmiş (21) }\end{array}$ & $\mathbf{p}^{\mathbf{a}}$ \\
\hline BAÖ & $5,05 \pm 5,24$ & $13,10 \pm 10,48$ & $0,001^{*}$ \\
BDÖ & $3,95 \pm 4,69$ & $10,19 \pm 6,99$ & $<0,001^{* *}$ \\
Depresif & $5 \pm 2,75$ & $5,81 \pm 2,87$ & 0,356 \\
Siklotimik & $6,74 \pm 4,80$ & $9,62 \pm 3,68$ & $0,010^{*}$ \\
Hipertimik & $8,58 \pm 4,67$ & $10,52 \pm 3,41$ & 0,095 \\
İrritabl & $3,68 \pm 3,61$ & $4,71 \pm 3,19$ & 0,130 \\
Anksiyöz & $5,53 \pm 4,71$ & $7,24 \pm 4,78$ & 0,175 \\
BIS dikkat & $16,24 \pm 2,77$ & $17,90 \pm 3,30$ & $0,033^{*}$ \\
\hline a mann whitney u test, ${ }^{*} \mathrm{p}<0,05, * *{ }^{*}<0,001$ & &
\end{tabular}

Çalışmaya dahil edilen AV'li hastalarda hastalık süresi ile anksiyete $(r=-0,515 \mathrm{p}=0,003)$ depresyon $(\mathrm{r}=-0,567 \mathrm{p}=0,001)$ ve yaşam kalitesi $(r=-0,378 \mathrm{p}=0,033)$ arasında negatif korelasyon saptadık. GAGS puanları ile irritabl mizaç $(\mathrm{r}=0,375 \mathrm{p}=0,005)$ ve dikkat ile ilgili dürtüsellik $(\mathrm{r}=0,290$ $\mathrm{p}=0,034)$ arasinda pozitif korelasyon saptand1. DYKI puanları ile anksiyete $(\mathrm{r}=0,562 \mathrm{p}<0,001)$ depresyon $(\mathrm{r}=0,600 \mathrm{p}<0,001)$ dikkat ile ilgili dürtüsellik ( $\mathrm{r}=0,277 \mathrm{p}=0,033)$ siklotimik mizaç $(r=0,429 \mathrm{p}=0,001)$ hipertimik mizaç $(\mathrm{r}=0,346 \mathrm{p}=0,007)$ irritabl mizaç $(\mathrm{r}=0,291 \mathrm{p}=0,025)$ ve anksiyöz mizaç $(\mathrm{r}=0,283$ $\mathrm{p}=0,030)$ puanları arasında pozitif korelasyon saptadık. Ayrıca dürtüsellik toplam puanları ile siklotimik mizaç $(\mathrm{r}=0,296$ $\mathrm{p}=0,003)$ irritabl mizaç $(\mathrm{r}=0,415 \mathrm{p}<0,001)$ anksiyöz mizaç $(\mathrm{r}=0,239 \mathrm{p}=0,017)$ arasinda pozitif korelasyon saptand .

\section{Tartışma}

$\mathrm{Bu}$ çalışmada AV'li hastalar ile sağlıklı kontroller arasında sosyodemografik özellikler, afektif mizaç, dürtüsellik, dermatolojik yaşam kalitesi, depresyon ve anksiyete puanları karşılaştırıldı. AV'li hastalarda siklotimik ve irritabl mizaç puanları ile toplam dürtüsellik puanı ve alt boyutları olan motor, dikkat ve tasarlanmamış dürtüsellik boyutları sağlıklı kontrollere göre anlamlı olarak yüksek bulunmuştur.

AV oldukça sık görülen bir dermatolojik bozukluk olmasına rağmen, hastaların mizacı ile ilgili çalışmalar sınırlı sayıdadır. Literatürde akneli bireylerin çekingen kişilik özellikleri gibi nörotik özelliklerin olduğunu savunan yazarların yanında kişilik özelliklerinin akne gelişiminde yeri olmadığını savunanlar da vardır $(10,25)$. Mizaç ve karakter envanteri kullanarak yapılan bir çalışmada bağımlılık, erdemlilikvicdanlılık, endişe, karamsarlık ve sosyal onaylama puanları, akne hastalarında kontrol grubuna göre istatistiksel olarak anlamlı seviyede yüksek bulunmuştur (26). Yine mizaç ve karakter envanteri kullanılarak yapılan başka bir çalışmada akneli bireylerin kendini yönetme puanları düşük bulunmuş ve bu durumun, hastanın tedaviyle ilgili süreçlerde problemler yaşamasına sebep olabileceği belirtilmiştir (27). Çalışmamızda AV'li hastalarda siklotimik ve irritabl mizaç puanlarını anlamlı ölçüde yüksek bulduk. Ayrıca depresyon puanları ile siklotimik ve irritabl mizaç arasında ilişki saptadık. İrritabl mizaç puanları yüksek bireyler karamsar, huzursuz, eleştirel, yoğun duygu dişa vurumu olan ve dürtüsel bireyler olarak tanımlanmıştır (28). AV'li hastaların yaşadığı anksiyete ve depresyon gibi duygularda, irritabl mizaç özelliklerinin de katkısı olabileceğini düşünmekteyiz. Önceki çalışmalarda depresyon ve anksiyete hastalarında yüksek siklotimik ve irritabl mizaç puanları gösterilmiştir $(29,30)$. Çalışmamız da siklotimik ve irritabl mizaç ile AV'li hastaların depresyon düzeyleri arasında anlamlı bir korelasyon vardı ve bizim sonuçlarımız yüksek siklotimik ve irritabl mizaç puanlarının hem depresyon hem de akne için yüksek risk oluşturduğunu göstermektedir. AV hastalık şiddeti ile irritabl mizaç puanları arasında pozitif korelasyon saptadık. Belirti şiddeti fazla olan AV hastalarında irritabl mizaç özelliklerinin de göz önünde bulundurulmasının tedaviye olumlu katkılarının olabileceğini düşünmekteyiz.

Çalışmamızda AV'li hastaların GADS puanları ile anksiyete ve depresyon puanları arasında anlamlı bir ilişki saptanmadı. İlginç olarak hastalık süresi arttıkça AV'li bireylerin anksiyete, depresyon düzeyleri ve yaşam kalitesi puanları azalmakta idi. Bu durum çalışmamızdaki AV'li bireylerin zamanla hastalığa karş1 uyum geliştirmiş olabileceklerini düşündürmektedir. Çalışmamızın aksine Öztürk ve ark.nın yaptıkları çalışmada akne şiddeti ile anksiyete düzeyi arasında pozitif korelasyon olduğu bildirilmiştir (26). Birçok çalışmada AV hastalarında depresyon ve anksiyete değerlerinin yüksek olduğu ve bunun hastaların yaşamlarında zorluklar oluşturduğu öne sürülmüştür $(31,32)$. AV hastalarında depresyon ve intihar eğilimlerinin arttığ1 bildirilmiştir $(33,34)$. Klinik olarak artan akne şiddeti, psikiyatrik tedavi gerektirecek düzeyde depresyon ve intihar düşüncesi ile ilişkilendirilmiştir (35). Çalışmamızda tasarlanmamış dürtüsellik, motor dürtüsellik ve dikkat ile ilgili dürtüsellik puanlarının yüksek olduğunu saptadık. Ayrıca dürtüsellik toplam puanları ile yaşam kalitesini belirleyen günlük aktivite, boş zaman değerlendirme ve okul-iş yaşantısı puanları arasında pozitif korelasyon saptandı. Dürtüsellik düzeyinde artış AV'li hastaların yaşam kalitesinde bozulma ile ilişkili bulundu. Dürtüselliğin intihar davranışları ile ilişkisi bilinmektedir $(36,37)$. AV hastalarında intihar davranışındaki bu artışın dürtüsellik ile açıklanabileceğini düşünmekteyiz.

Yapılan çalışmalar AV' in diğer kronik sistemik hastalıklar gibi yaşam kalitesini etkileyebileceğini göstermektedir $(4,38,39)$. Dermatoloji hastalarında depresyon ve anksiyete düzeylerinin klinik özellikler ile ilişkinin belirlenmesi için yapılmış bir araştırmada, deri hastalıklarının yaşam kalitesini bozduğu ve bu bozulmanın depresyon ve anksiyete riskini de artıracağ 1 bildirilmiştir (40). Dış görünüş ve beden algısının mizaç ve karakter özellikleri ile ilişkili olabileceğine dair çalışmalar vardır (41). Literatürle uyumlu olarak çalışmamızda AV'li bireylerin anksiyete ve depresyon puanları arttıkça yaşam kalitelerinin bozulduğunu belirledik. AV'li bireylerin yaşadığı anksiyete ve depresyonun, hastalığın belirti ve semptomlarını arttırdığı, bireyin yaşam kalitesini belirleyen günlük aktivitelerinde, boş zaman değerlendirmede, okul-iş yaşantısını, kişisel ilişkilerini ve tedavinin gidişatını olumsuz yönde etkilediğini tespit ettik. Çalışmamızda hastaların \%64,4'ünde yaşam kalitesi hastalıktan dolayı az etkilenmiş veya hiç etkilenmemiş olarak saptanırken, \%35,6'sınde orta düzeyde veya çok etkilenmişti. Bu sonuç, AV'li hastaların 
yaşam kalitesinin olumsuz etkilendiğini gösteren literatür çalışma verilerini desteklemektedir (42-44).

Çalışmamız AV'li hastaları mizaç ve dürtüsellik ile yaşam kalitesi, depresyon, anksiyete arasındaki ilişki açısından değerlendiren ilk çalışmadır. $\mathrm{Bu}$ bulgular, mizaç ve dürtüsellik ile AV arasındaki ilişkiyi ve hastalığın seyri üzerine olan potansiyel etkisi hakkındaki bakış açımızı genişletmektedir. Klinisyenlerin AV hastalarında mizaç ve dürtüsellik taranması, hastalığın şiddetlenme faktörlerini daha doğru değerlendirmelerine yardımcı olabilir, ayrıca kronik cilt hastalıkları sürecinde mizaç özelliklerinin gelişimini anlayabilmelerini sağlayacaktır.

\section{Sonuc}

Sonuç olarak, mizaç ve karakter özelliklerini anlamak, bu kronik cilt hastalıklarının tedavisi sırasında hastalar ve doktorlar arasında işbirliğine dayalı bir iletişimin kurulmasında temel oluşturacaktır. Ayrıca bu hastalarda multidisipliner yaklaşımın önemli olduğu görülmekte olup, çalışmamızın mizaç özelliklerinin ve dürtüsellik düzeylerinin AV hastalığındaki rolünün anlaşılmasında daha ileri çalışmalara katkı sağlayacağına inanıyoruz. Bu çalışma, AV hastalığına biyopsikososyal tıp modeline göre yaklaşmak ve tedavi planını oluşturmanın önemine dikkat çekmektedir.

\section{Kaynaklar}

1. Ak M, Haciomeroglu B, Turan Y, Lapsekili N, Doruk A, Bozkurt A, Akar A. Temperament and character properties of male psoriasis patients. J Health Psychol 2012; 17(5): 774-81. 2. Litaiem N, Youssef S, Jabeur K, Dhaoui MR, Doss N. Affective temperament profile in psoriasis patients in Tunisia using TEMPS-A. J Affect Disord 2013; 151(1): 321-4.

3. Tucker P. Bald Is Beautiful? Journal of Health Psychology 2009; 14(1): 142-51.

4. Demirçay Z, Senol A, Seckin D, Demir F. Reliability of Turkish version of acne quality of life scale in patients with acne vulgaris. Türkderm 2006; 40: 94-7.

5. Lasek RJ, Chren MM. Acne vulgaris and the quality of life of adult dermatology patients. Arch Dermatol 1998; 134: 454-58.

6. Dreno B, Poli F. Epidemiology of acne. Dermatology 2003; 206: 7-10.

7. Goulden V, Stables GI, Cunliffe WJ. Prevalence of facial acne in adults. J Am Acad Dermatol 1999; 41: 577-80.

8. White GM. Recent findings in the epidemiologic evidence, classification, and subtypes of acne vulgaris. J Am Acad Dermatol 1998; 39: 34-7.

9. Gois C, Akiskal H, Akiskal K, Figueira ML. The relationship between temperament, diabetes and depression. J Affect Disord 2012; 142: 67-71.

10. Lim CC, Tan TC. Personality, disability and acne in college students. Clin Exp Dermatol 1991; 16(5): 371-3.

11. Gupta MA, Gupta AK, Schork NJ. Psychosomatic study of self excoriative behavior among male acne patient. Int $\mathrm{J}$ Dermatol 1994; 33: 846-8.

12. Rapp DA, Brenes GA, Feldman SR, Fleischer AB Jr, Graham GF, Dailey M, Rapp SR. Anger and acne: implications for quality of life, patient satisfaction and clinical care. Br J
Dermatol 2004; 151(1): 183-9.

13. Rubinow DR, Peck GL, Squillace KM, Gantt GG. Reduced anxiety and depression in cystic acne patients after successful treatment with oral isotretinoin. J Am Acad Dermatol 1987; 17(1): 25-32.

14. Özcan Y, Özcan H, Ünal S. Akne Vulgarisli Bireylerde Kişilik Özellikleri. Klinik Psikiyatri 2000; 3: 56-60.

15. Akiskal HS, Akiskal KK, Haykal RF, Manning JS, Connor PD. TEMPS-A: progress towards validation of a selfrated clinical version of the Temperament Evaluation of the Memphis, Pisa, Paris, and San Diego Autoquestionnaire. J Affect Disord 2005; 85(1-2): 3-16.

16. Vahip S, Kesebir S, Alkan M, Yazici O, Akiskal KK, Akiskal HS. Affective temperaments in clinically-well subjects in Turkey: initial psychometric data on the TEMPS-A. J Affect Disord 2005; 85(1-2): 113-25.

17. Beck AT, Epstein N, Brown G, Steer RA. An inventory for measuring clinical anxiety: psychometric properties. J Consult Clin Psychol 1988; 56(6): 893-7.

18. Ulusoy M, Sahin N, Erkmen H. Turkish version of the Beck Anxiety Inventory: Psychometric properties. Journal of Cognitive Psychotherapy 1998; 12(9): 163-72.

19. Beck AT, Ward CH, Mendelson M, Mock J, Erbaugh J. An inventory for measuring depression. Arch Gen Psychiatry 1961; 4: 561-71.

20. Hisli N. The validity of the Beck Depression Inventory. Turkish Journal of Psychology 1988; 6(8): 118-22.

21. Doshi A, Zaheer A, Stiller MJ. A comparison of current acne grading systems and proposal of a novel system. Int J Dermatol 1997; 36(6): 416-8.

22. Finlay AY. Quality of life measurement in dermatology: a practical guide. Br J Dermatol 1997; 136: 305-14.

23. Oztürkcan S, Ermertcan AT, Eser E, Sahin MT. Cross validation of the Turkish version of dermatology life quality index. Int J Dermatol 2006; 45(11): 1300-7.

24. Güleç H, Tamam L, Güleç MY, Turhan M, Karakuş G, Zengin M, Stanford MS. Psychometric Properties of the Turkish Version of the Barratt Impulsiveness Scale-11. Bulletin of Clinical Psychopharmacology 2008; 18: 251-8.

25. Koo J. Psychodermatology: A practical manual for clinicians. Curr Probl Dermatol 1995; 7(6): 204-32.

26. Ozturk P, Orhan FO, Ozer A, Karakas T, Oksuz AN, Yetisir NY. Assessment of temperament and character profile with anxiety and depression in patients with acne. Balkan Medical Journal 2013; 30(2): 161-66.

27. Sönmez İ, Mullaaziz D, Kaptanoğlu A, Tosun Ö. Akne Vulgaris Hastalarında Karakter ve Mizaç Özellikleri. Yeni Symposium 2017; 55(3): 2-6.

28. Akiskal HS, Mallya G. Criteria for the "soft" bipolar spectrum: treatment implications. Psychopharmacol Bull 1987; 23(1): 68-73.

29. Mazzarini L, Pacchiarotti I, Colom F, Sani G, Kotzalidis GD, Rosa AR, Sanna L, De Rossi P, Girardi N, Bonnin CM, Sanchez-Moreno J, Vazquez GH, Gasto C, Tatarelli R, Vieta E. Predominant polarity and temperament in bipolar and unipolar affective disorders. J Affect Disord 2009; 119(1-3): 28-33. 
30. Şair YB, Dereboy F, Kesebir S. Depresif ucun sınıflandırılmasında kimlik ve mizaç özellikleri. Anatolian Journal of Psychiatry 2013; 14: 210-7.

31. Kilkenny M, Stathakis V, Hibbert ME, Patton G, Caust J, Bowes G. Acne in Victorian adolescents: associations with age, gender, puberty and psychiatric symptoms. J Paediatr Child Health 1997; 33(5): 430-3.

32. Takahashi N, Suzukamo Y, Nakamura M, Miyachi Y, Green J, Ohya Y, Finlay AY, Fukuhara S; Acne QOL Questionnaire Development Team. Japanese version of the Dermatology Life Quality Index: validity and reliability in patients with acne. Health Qual Life Outcomes 2006; 4: 46.

33. Gupta MA, Gupta AK. Depression and suicidal ideation in dermatology patients with acne, alopecia areata, atopic dermatitis and psoriasis. Br J Dermatol 1998; 139(5): 846-50. 34. Fried RG, Wechsler A. Psychological problems in the acne patient. Dermatol Ther 2006; 19(4): 237-40.

35. Thomas DR. Psychosocial effects of acne. J Cutan Med Surg 2004; 8(4): 3-5.

36. Corruble E, Damy C, Guelfi JD. Impulsivity: a relevant dimension in depression regarding suicide attempts? J Affect Disord 1999; 53(3): 211-5.

37. Swann AC, Moeller FG, Steinberg JL, Schneider L, Barratt ES, Dougherty DM. Manic symptoms and impulsivity during bipolar depressive episodes. Bipolar Disord 2007; 9(3): 206-12.
38. Jones-Caballero M, Chren MM, Soler B, Pedrosa E, Peñas PF. Quality of life in mild to moderate acne: relationship to clinical severity and factors influencing change with treatment. J Eur Acad Dermatol Venereol 2007; 21(2): 219-26.

39. Krejci-Manwaring J, Kerchner K, Feldman SR, Rapp DA, Rapp SR. Social sensitivity and acne: the role of personality in negative social consequences and quality of life. Int $\mathbf{J}$ Psychiatry Med 2006; 36(1): 121-30.

40. Yazici K, Baz K, Yazici AE, Köktürk A, Tot S, Demirseren D, Buturak V. Disease-specific quality of life is associated with anxiety and depression in patients with acne. J Eur Acad Dermatol Venereol 2004; 18(4): 435-9.

41. Gurok MG, Kılıç F, Sağlam S, Gürok NG, Kuloğlu MM, Yildırım AM. Patients without psychopathology applying for aesthetic rhinoplasty may display elevated harm avoidance and reduced self-directedness: a cross-sectional, case-control study, Psychiatry and Clinical Psychopharmacology 2019; 10.1080/24750573.2019.1605666. [Epub ahead of print].

42. Erturan İ, Aktepe E, Kocaman O, Sönmez Y, Başak PY, Ceyhan AM, Akkaya VB. Evaluation of acne quality of life, loneliness and life satisfaction levels in adolescents with acne vulgaris. Türkderm 2014; 48(4): 172-76.

43. Öztürkcan S, Aydemir Ö, İnanır I. Akne vulgarisli hastalarda yaşam kalitesi. T Klin J Dermatol 2002; 12: 131-4. 44. Acıöz E, Gökdemir G, Köşlü A. Dermatolojide yaşam kalitesi. Türkderm 2003; 37(1): 16-23. 